\section{UV Irradiance Increases Development of Red Skin Color and Anthocyanins in 'Hakuho' Peach}

\author{
Ikuo Kataoka ${ }^{1}$ and Kenji Beppu ${ }^{2}$ \\ Department of Horticulture, Faculty of Agriculture, Kagawa University, Miki, \\ Kagawa 761-0795, Japan
}

Additional index words. anthocyanin, Prunus persica, UV-proof film, UV irradiation

Abstract. The contribution of the UV light component on the skin coloration was determined in 'Hakuho' peach. Detached fruit partially covered with a UV-proof polyvinylchloride (PVC) film and a polyethylene film were exposed to sunlight for $\mathbf{4}$ days. Red coloration of the fruit and anthocyanin content in the skin were considerably reduced with the UV-proof PVC film. Irradiation with a UV fluorescent lamp at $3.58 \mathrm{~W} \cdot \mathrm{m}^{-2}$ markedly enhanced the red color development, while white fluorescent light at $120 \mu \mathrm{mol} \cdot \mathrm{m}^{-2} \cdot \mathrm{s}^{-1}$ did not affect the coloration. UV irradiation also increased the anthocyanin content in the cultured skin discs with increasing irradiance up to above $7.3 \mathrm{~W} \cdot \mathrm{m}^{-2}$. These results suggest that the $\mathrm{UV}$ component contributes significantly to the enhancement of the fruit coloration by sunlight exposure.

In peach, the development of red skin coloration of fruit markedly depends on the light conditions (Bible and Singha, 1993; Correlli-Grappadelli and Coston, 1991; Marini, 1985). Erez and Flore (1986) showed that the exposure to full sunlight for $3 \mathrm{~d}$ stimulated considerably color development at the end of stage II of fruit development in 'Redhaven' peach. They also reported that red color was reduced with increasing shading. The fruit inside or at lower position in the canopy usually showed poorer coloration than those outside or at higher position due to reduced light exposure. Techniques such as summer pruning (Myers, 1993), and the use of metalized reflective film mulches (Layne et al., 2001) have been used to increase light penetration into the tree and consequently improve fruit coloration.

The evaluation of the light conditions for fruit coloration of peach, to date, has been based on solar radiation, but the effect of specific wavelength of light has not been elucidated. For other fruit, producing anthocyanin pigments in the skin such as apple (Arakawa, 1988; Arakawa et al., 1985; Chalmers and Faragher, 1977), sweet cherry (Arakawa, 1993), and grapes (Kataoka et al., 2003), the role of UV light in the fruit coloration has been demonstrated. We previously showed that the fruit coloration of 'Satonishiki' sweet cherry was enhanced mainly by irradiation of UV light compared with white light (Kataoka et al., 1996). The present study was conducted to determine the contribution of the UV light component on the skin coloration of detached fruit of 'Hakuho', a common midseason peach cultivar in Japan.

\section{Materials and Methods}

Plant materials. Yellow-green fruit were collected at the beginning of stage III of fruit

Received for publication 12 Aug. 2002. Accepted for publication 10 Feb. 2003.

${ }^{1}$ Professor.

${ }^{2}$ Assistant professor. growth, 3 weeks before harvesting, from 4year-old 'Hakuho' peach trees on 'Nagano wild peach' seedling rootstocks grown at the experimental field of Kagawa University, Kagawa, Japan. Developing fruit were covered with paper bags to prevent insect damage and fungal infection from the beginning of growth stage II until the collection for 4 weeks.

Light measurements. The radiant energy of light was measured using a spectroradiometer (LI-1800, LI-COR Inc., Lincoln, Nebr.). The level of photosynthetic photon flux $(P P F)$ was determined using a quantum sensor (LI190SA, LI-COR) and irradiance of UV light was measured by UV sensor (SD104Acos 320-400 nm; Macam Photometrics Ltd., Scotland) equipped with a data logger (LI1000; LI-COR).

Experiment 1: Elimination of UV component in sunlight. The equatorial part of each fruit was covered with a $3 \times 8-\mathrm{cm}$ stripe consisting of two treatments: $0.075-\mathrm{mm}-$ thick UV-proof film (Cut Ace, Mitsubishi chemical MKV, Tokyo) and 0.04-mm-thick polyethylene film (Seinichi Co., Tokyo). The characteristics of these films in the transmittance of sunlight are shown in Fig. 1. Fruit were exposed to sunlight with the cheek side up. The treatment started at $0800 \mathrm{HR}$ and continued for $4 \mathrm{~d}$. The fruit were actually exposed to sunlight for $9 \mathrm{~h} \cdot \mathrm{d}^{-1}$.

Experiment 2: Irradiation of UV fluorescent light. Fruit were irradiated with UV light and white light using FL20SBLB (peak wavelength:352 nm, Toshiba, Tokyo, Japan) and FL20S-SS (Toshiba) fluorescent tubes, respectively. The white light tubes were wrapped with UV-proof PVC film to eliminate UV components emitted at a low intensity. The spectral irradiance of these tubes is shown in Fig. 2. The irradiation was applied in a steel framework $60 \mathrm{~cm}(\mathrm{~W}) \times$ $30 \mathrm{~cm}(\mathrm{D}) \times 40 \mathrm{~cm}(\mathrm{H})$ covered with black felt. Fruit were placed $25 \mathrm{~cm}$ away from the light source. The intensity of the irradiation at the surface of the fruit is shown in Table 1. Five fruit per treatment were continuously irradiated for $96 \mathrm{~h}$.

Experiment. 3: Intensity of UV irradiation. Fruit skin discs were irradiated at different intensities of UV light. Skin discs measuring $2 \mathrm{~cm}$ in diameter and $3 \mathrm{~mm}$ in thickness were obtained from the equatorial part of each fruit. Three discs were placed in a $6 \mathrm{~cm}$ in diam sterile plastic petri dish (MS-11600; Sumitomo Bakelite Co., Ltd., Tokyo) containing $3 \mathrm{~mL}$ of a filter-sterilized solution of $0.4 \mathrm{~m}$ sucrose and $0.05 \% \mathrm{~L}$-ascorbic acid on one layer of filter paper. The light source and the equipment were the same as those in Expt. 2. The intensity of irradiation was adjusted by placing several layers of shade screen over the petri dish. The intensity was monitored beneath the plastic cover. The cultures were continuously irradiated for $96 \mathrm{~h}$.

Skin color measurement. The $\mathrm{L}^{*} \mathrm{a} * \mathrm{~b} *$ values were measured at three positions $5 \mathrm{~mm}$ apart for the irradiated side of the fruit using a chromameter (CR 200; Minolta, Tokyo).

Anthocyanin measurement. Three skin discs $9 \mathrm{~mm}$ in diameter were collected from individual parts of the treated fruit or skin discs. Anthocyanin was extracted overnight with $10 \mathrm{~mL} 1 \% \mathrm{HCl}$-methanol at $5{ }^{\circ} \mathrm{C}$ in the dark, and the absorbance of the extract was measured at $530 \mathrm{~nm}$ by a spectrophotometer (Ubest-30; Japan Spectroscopic Co., Ltd., Tokyo).

Fig. 1. Transmittance of polyethylene and UV-proof PVC films in the range of (A) 300 to $1100 \mathrm{~nm}$ and (B) 300 to $450 \mathrm{~nm}$ of sunlight
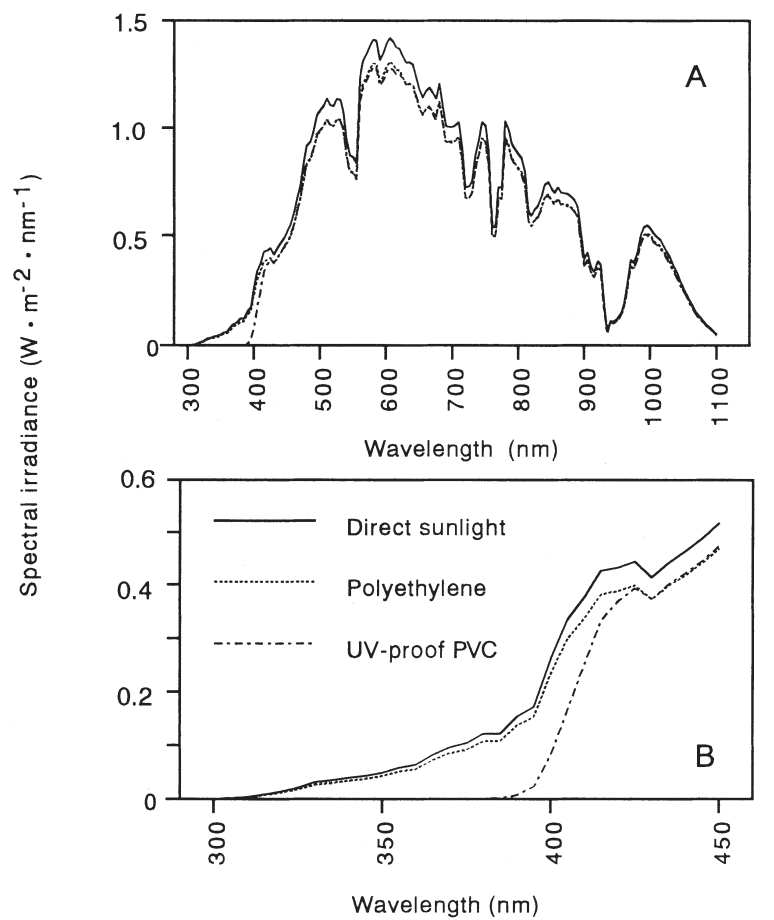


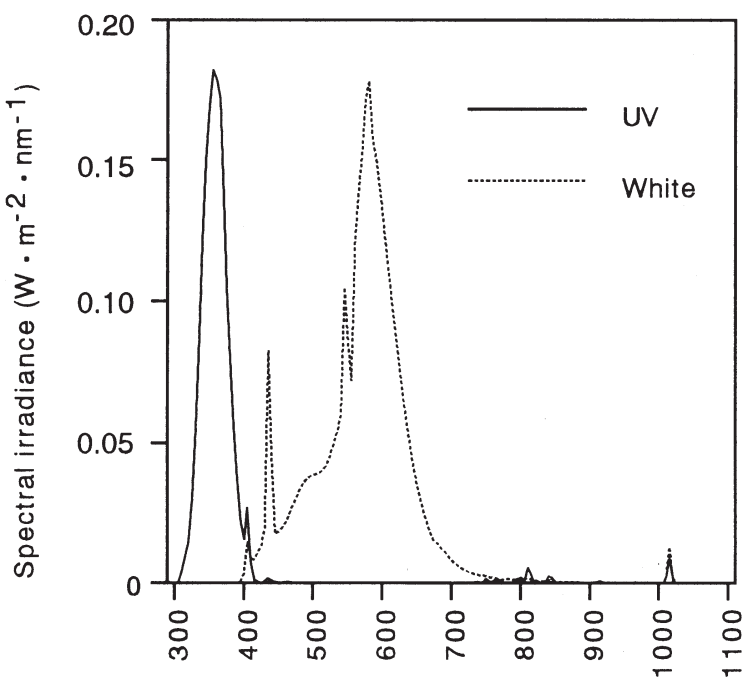

Wavelength $(\mathrm{nm})$

Table 1. Effect of UV and white irradiation on the accumulation of anthocyanin in the skin of 'Hakuho' peach. ${ }^{2}$

\begin{tabular}{|c|c|c|c|}
\hline \multirow[b]{2}{*}{$\begin{array}{l}\text { Irradiation } \\
\text { source }\end{array}$} & \multicolumn{2}{|c|}{ Irradiance } & \multirow{2}{*}{$\begin{array}{c}\text { Anthocyanin } \\
\text { (O.D. at } \\
530 \mathrm{~nm})\end{array}$} \\
\hline & $\begin{array}{c}P P F \\
\left(\mu \mathrm{mol} \cdot \mathrm{m}^{-2} \cdot \mathrm{s}^{-1}\right)\end{array}$ & $\begin{array}{c}\mathrm{UV}^{\mathrm{y}} \\
\left(\mathrm{W} \cdot \mathrm{m}^{-2}\right)\end{array}$ & \\
\hline Dark & 0 & 0 & $0.006 \mathrm{~b}$ \\
\hline White fluorescent ${ }^{x}$ & 120 & 0 & $0.010 \mathrm{~b}$ \\
\hline UV fluorescent ${ }^{\mathrm{w}}$ & 0.34 & 3.58 & $0.118 \mathrm{a}$ \\
\hline
\end{tabular}

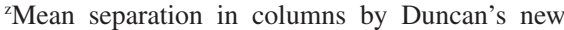
multiple range test at $5 \%$ probability.

UV range of 320 to $400 \mathrm{~nm}$ was measured.

${ }^{x}$ FL20S-BLB (peak wavelength $=352 \mathrm{~nm}$ ). ${ }^{\mathrm{w}} \mathrm{FL} 20 \mathrm{~S}-\mathrm{SS}$.

\section{Results}

Experiment 1: Elimination of UV component in sunlight. Polyethylene and UV-proof PVC films reduced $P P F$ to $84 \%$ and $88 \%$ of full sunlight, respectively. UV-proof PVC film penetrated only $0.04 \%$ of the UV region in sunlight, while the polyethylene film transmitted $78 \%$ of the light. At noon, the maximum temperature of the fruit skin under both films was $37 \pm 2{ }^{\circ} \mathrm{C}$, compared with $35 \pm 2{ }^{\circ} \mathrm{C}$ for the uncovered skin. One day after the onset of exposure to sunlight, the red coloration began to develop in those parts of the fruit that were covered with polyethylene film or had no covering. These parts turned reddish-pink at the end of treatment, whereas those parts covered with UV-proof PVC film remained whitish-yellow (Fig. 3). The value of $a^{*}$, which was closely related to red coloration and anthocyanin content, was significantly lower in the fruit skin covered with UV-proof PVC (Table 2).

Experiment 2: Irradiation of UVfluorescent light. The color of the fruit kept in dark did not change during the 4 day exposure period. Artificial irradiation with $\mathrm{UV}$ at $3.58 \mathrm{~W} \cdot \mathrm{m}^{-2}$ markedly enhanced red coloration. White fluorescent light at the rate of $120 \mu \mathrm{mol} \cdot \mathrm{m}^{-2} \cdot \mathrm{s}^{-1}$ showed no significant effect on the color development (Fig. 4). Anthocyanin content in the skin was significantly increased by UV irradiation (Table. 1).

Experiment 3: Intensity of UV irradiation.
Fig.2. Spectral irradiance of UV and white fluorescent lamps. As the lighting sources of UV and white, FL20SBLB and FL20S-SS (Toshiba, Tokyo) were used, respectively.

Red coloration of the skin discs started to develop $2 \mathrm{~d}$ after the onset of irradiation at a higher intensity of UV light. After $96 \mathrm{~h}$ of irradiation, anthocyanin content in the skin increased along with the increasing intensity of UV irradiation (Fig. 5). The red coloration was clearly observed in the skin discs irradiated with UV light above $1.6 \mathrm{~W} \cdot \mathrm{m}^{-2}$ intensity (Fig. 6).

\section{Discussion}

Elimination of the UV component from sunlight markedly reduced the coloration and the anthocyanin content in the skin of 'Hakuho' peach fruit. Kliewer (1977) grape berries was markedly inhibited when the berries were exposed to $37 / 32{ }^{\circ} \mathrm{C}$, day/night under high solar irradiation. In this experiment, however, the production of anthocyanin under the polyethylene film, compared with the UV-proof film showed that temperature stress was not a key factor affecting the response as both treatments had elevated temperatures. On the other hand, the artificial irradiation by UV fluorescent light increased anthocyanin content in whole fruit and skin discs. These results indicate that the UV component mainly contributed to enhance the fruit coloration by sunlight. The response of the skin discs to different intensities of UV irradiation indicated reported that the anthocyanin formation in

that an intensity $>1.6 \mathrm{~W} \cdot \mathrm{m}^{-2}$ is necessary for the development of red color in this cultivar. Inside or in the lower part of the tree canopy, severe reduction in the UV component may occur concomitantly with the decrease in sunlight transmission (Bible and Singha, 1993). Cultural practices such as summer pruning, leaf removal or use of metalized reflective films could improve both UV and $P P F$ exposure to fruit (Layne et al., 2001; Myers, 1993).

As for the mechanism of the enhancement of anthocyanin synthesis with UV light, UV irradiation has been reported to increase the phenylalanine ammonia-lyase (PAL) activity that is involved in phenol synthesis in apple (Farager and Chalmers, 1977). The PAL activity is controlled by phytochrome with a low ratio of red to far-red light (R/FR) suppressing PAL and reducing anthocyanin synthesis (Mancinelli, 1985). Smart et al. (1988) have shown that R/FR ratio decreases under the canopy of grape vine and that red light supplementation enhances the accumulation of anthocyanin in the berry skin. The involvement of UV-A-blue (cryptochrome) and UV-B receptors in the gene expression of PAL and chalcone synthase has also been demonstrated in several plant tissues and cells (Fuglevand et al., 1996; Takeda et al., 1997). In peach fruit, it is also likely that the light transduction pathways inducing the gene expression of these enzymes involved in the anthocyanin synthesis are mediated by these receptors. Detailed investigations on the action spectra in the UV region for anthocyanin synthesis should be conducted to gain better understand the role of light in improving fruit coloration.

\section{Literature Cited}

Arakawa, O., Y. Hori, and R. Ogata. 1985. Relative effectiveness and interaction of ultraviolet-B,

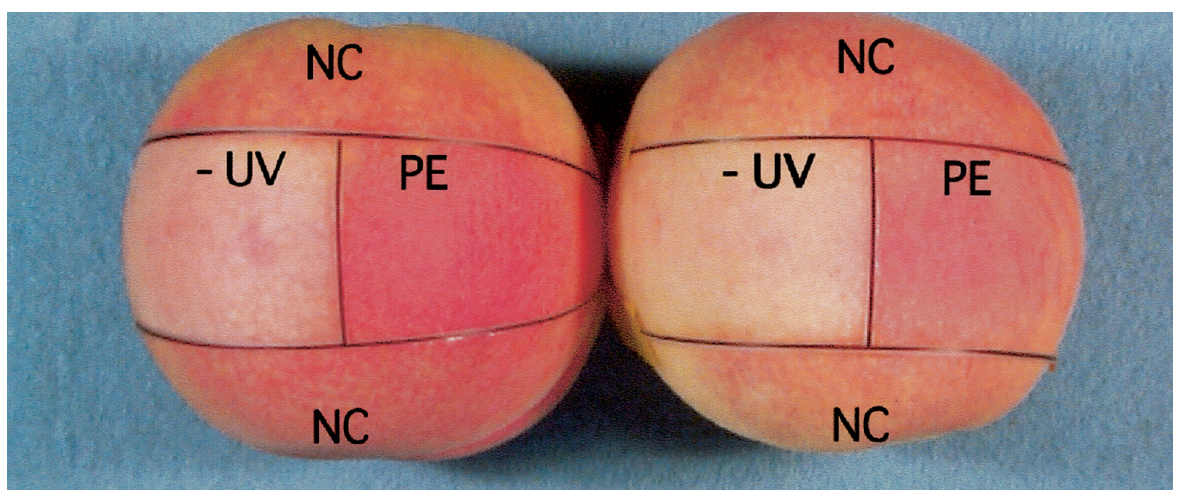

Fig. 3. Appearance of 'Hakuho' peach fruit partially covered with polyethylene and UV-proof films after irradiation with sunlight for $4 \mathrm{~d}$. $\mathrm{PE}=$ polyethylene, $-\mathrm{UV}=\mathrm{UV}$-proof $\mathrm{PVC}, \mathrm{NC}=$ no cover.

Table 2. Fruit coloration and accumulation of anthocyanin in 'Hakuho' peach under natural sunlight and partialy covered with polyethylene and UV-proof PVC films.

\begin{tabular}{|c|c|c|c|c|c|c|}
\hline \multirow[b]{3}{*}{ Treatment } & \multicolumn{2}{|c|}{ Irradiance } & \multirow{3}{*}{$\begin{array}{c}\text { Anthocyanin } \\
\text { (O.D. at } 530 \mathrm{~nm})\end{array}$} & \multirow{2}{*}{\multicolumn{3}{|c|}{ Chromameter value }} \\
\hline & $P P F$ & $\mathrm{UV}^{2}$ & & & & \\
\hline & $\left(\mu \mathrm{mol} \cdot \mathrm{m}^{-2} \cdot \mathrm{s}^{-1}\right)$ & $\left(\mathrm{W} \cdot \mathrm{m}^{-2}\right)$ & & $\mathrm{L}^{*}$ & $a^{*}$ & $\mathrm{~b}^{*}$ \\
\hline No cover & 1550 & 14.70 & $0.074 \mathrm{a}$ & $67.4 b^{y}$ & $18.8 \mathrm{~b}$ & $21.7 \mathrm{a}$ \\
\hline Polyethylene & 1300 & 11.50 & $0.114 \mathrm{a}$ & $59.5 \mathrm{~b}$ & $27.1 \mathrm{a}$ & $20.7 \mathrm{ab}$ \\
\hline UV-proof PVC & 1360 & 0.06 & $0.016 \mathrm{~b}$ & $72.2 \mathrm{a}$ & $8.4 \mathrm{c}$ & $19.0 \mathrm{~b}$ \\
\hline
\end{tabular}

${ }^{2} \mathrm{UV}$ range of 320 to $400 \mathrm{~nm}$ was measured.

yean separation in columns by Duncan's new multiple range test. Means within a column followed by the same letter are not significantly different at $5 \%$ probability. 


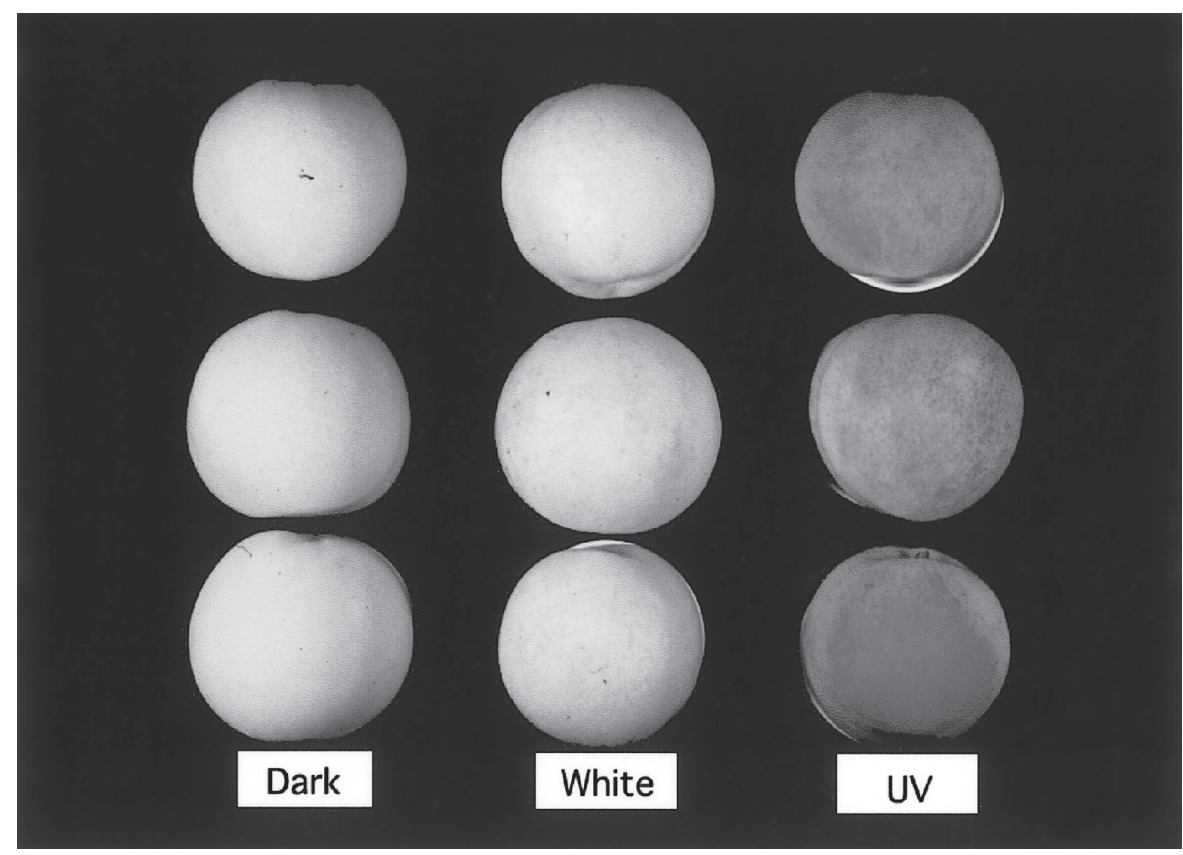

Fig. 4. Appearance of 'Hakuho' peach fruit after irradiation with white and UV fluorescent lights where lighting sources of UV and white were FL20S-BLB and FL20S-SS (Toshiba, Tokyo), respectively. Fruit kept without lighting were shown as dark.

Fig. 5. Accumulation of anthocyanin in the skin discs of 'Hakuho' peach fruit after irradiation with UV fluorescent light for $96 \mathrm{~h}$ using FL20S-BLB (peak wavelength $=352 \mathrm{~nm}$, Toshiba, Tokyo) as the source. Intensity of UV range of 320 to $400 \mathrm{~nm}$ was measured. Vertical bars indicate SE of the mean $(n=9)$.

red and blue light in anthocyanin synthesis of apple fruit. Physiol. Plant. 64:323-327.

Arakawa, O. 1988. Photoregulation of anthocyanin synthesis in apple fruit under UV-B and red light. Plant Cell Physiol. 29:1385-1389.

Arakawa, O. 1993. Effect of ultraviolet light on anthocyanin synthesis in light-colored sweet cherry cv. Sato Nishiki. J. Jpn. Soc. Hort. Sci. 62:543-546.

Bible, B.B. and S. Singha. 1993. Canopy position influences CIELAB coordinates of peach color. HortScience 28:992-993.

Chalmers, D.J. and J.D. Faragher. 1977. Regulation of anthocyanin synthesis in apple skin: I. Comparison of the effects of cycloheximide, ultraviolet light, wounding and maturity. Austral. J. Plant Physiol.4:111-121.

Corelli-Grappadelli, L. and D.C. Coston. 1991. Thinning pattern and light environment in peach tree canopies influences fruit quality. HortScience 26:1464-1466.

Erez, A. and J.A. Flore. 1986. The quantitative effect of solar radiation on 'Redhaven' peach fruit skin color. HortScience 21:1424-1426.

Faragher, J.D. and D.J. Chalmers. 1977. Regulation of anthocyanin synthesis in apple skin: III. Involvement of phenylalanine ammonia-lyase. Austral. J. Plant Physiol. 4:133-141.

Fuglevand, G., A. Jackson, and G. I. Jenkins. 1996. UV-B, UV-A, and blue light signal transduction

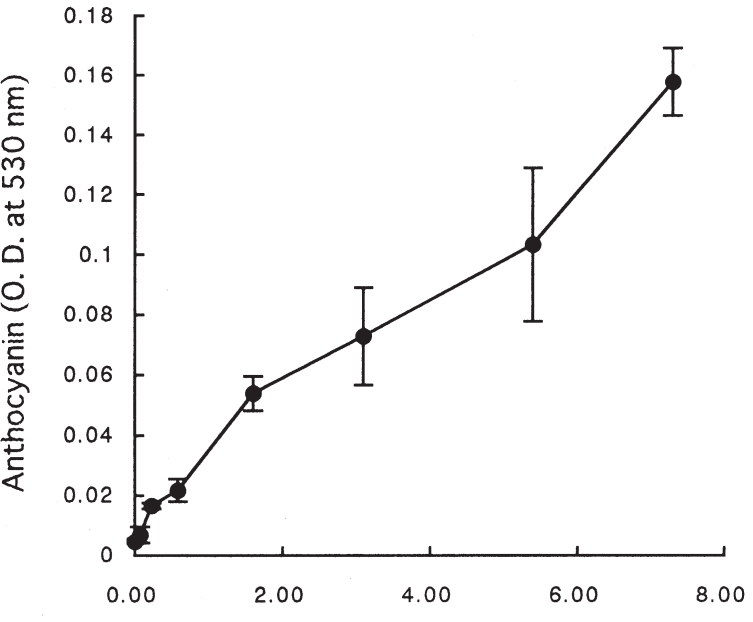

UV light intensity $\left(\mathrm{W} \cdot \mathrm{m}^{-2}\right)$

pathways interact synergistically to regulate chalcone synthase gene expression in Arabidopsis. Plant Cell 8:2347-2357.

Kataoka, I., K. Beppu , A. Sugiyama, and T. Taira. 1996. Enhancement of coloration of "Satoh-nishiki" sweet cherry fruit by postharvest irradiation with ultraviolet radiation. Environ. Control Biol. 34:313-319.

Kataoka, I., A. Sugiyama, and K. Beppu. 2003. Role of ultraviolet radiation in accumulation of anthocyanin in berry section of 'Gros Colman' grapes (Vitis vinifera L.). J. Jpn. Soc. Hort. Sci. 72:1-6.

Kliewer, W.M. 1977. Influence of temperature, solar radiation and nitrogen on coloration and composition of Emperor grapes. Amer. J. Enol. Viticult. 28:96-103

Layne, D.R., Z. Jiang, and J.W. Rushing. 2001. Tree fruit reflective film improves red skin coloration and advanced maturity in peach. HortTechnology 11:234-242.

Marini, R.P. 1985. Vegetative growth, yield, and fruit quality of peach as influenced by dormant 


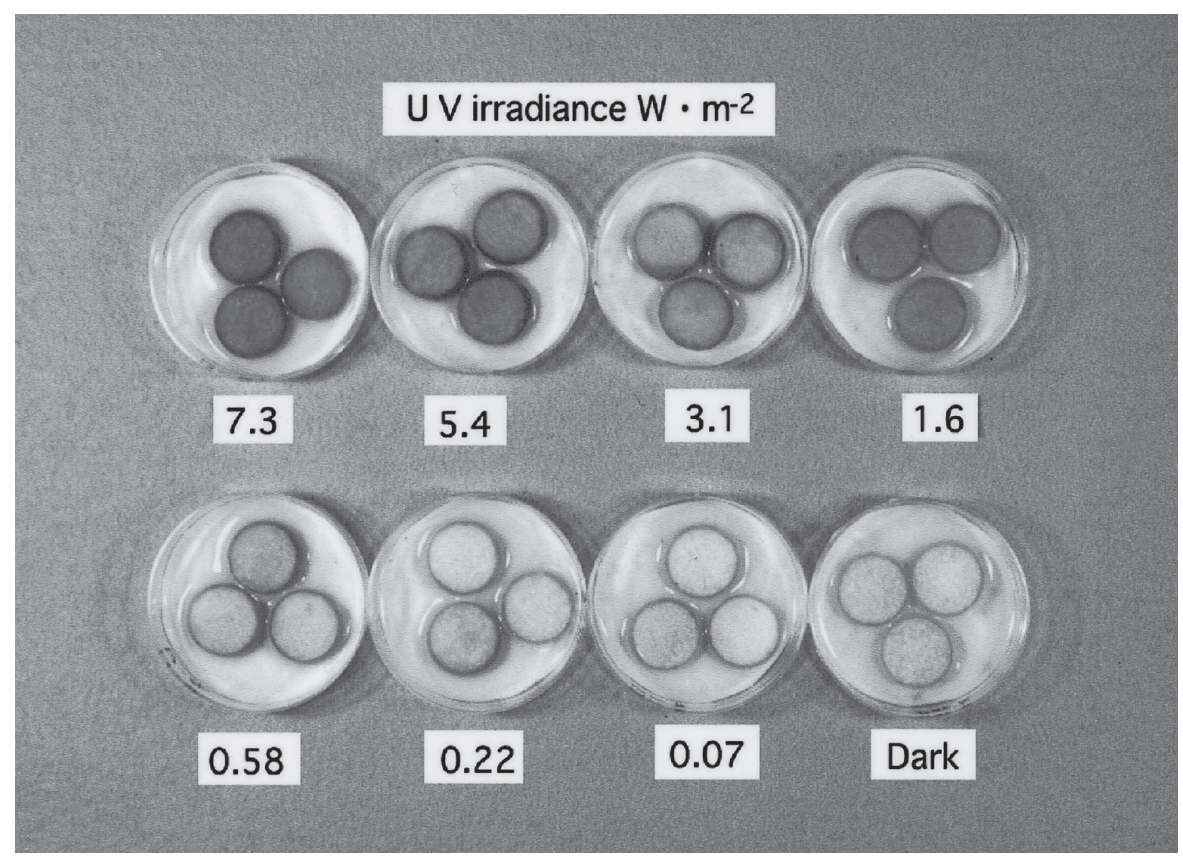

Fig. 6. Appearance of skin disc colors of 'Hakuho' peach fruit after irradiation with UV fluorescent light for $96 \mathrm{~h}$. As the lighting source, FL20S-BLB (Toshiba, Tokyo) was used.

pruning, summer pruning, and summer topping. J. Amer. Soc. Hort. Sci. 110:133-139.

Mancinelli,A.L. 1985.Light-dependent anthocyanin synthesis: A model system for the study of plant photomorphogenesis. Bot. Rev. 51:107-157.

Myers, S.C. 1993. Preharvest watersprout removal influences canopy light relations, fruit quality, and flower bud formation of 'Redskin' peach trees. J. Amer. Soc. Hort. Sci. 118:442-445.
Smart, R.E., S.M. Smith, and R.V. Winchester. 1988. Light quality and quantity effects on fruit ripening of 'Cabernet Sauvignon'. Amer. J. Enol. Viticult. 39:250-258.

Takeda, J., Y. Ozeki, and K. Yoshida. 1997. Action spectrum for induction of promoter activity of phenylalanine ammonia-lyase gene by UV in carrot suspension cells. Photochem. Photobiol. 66:464-470. 